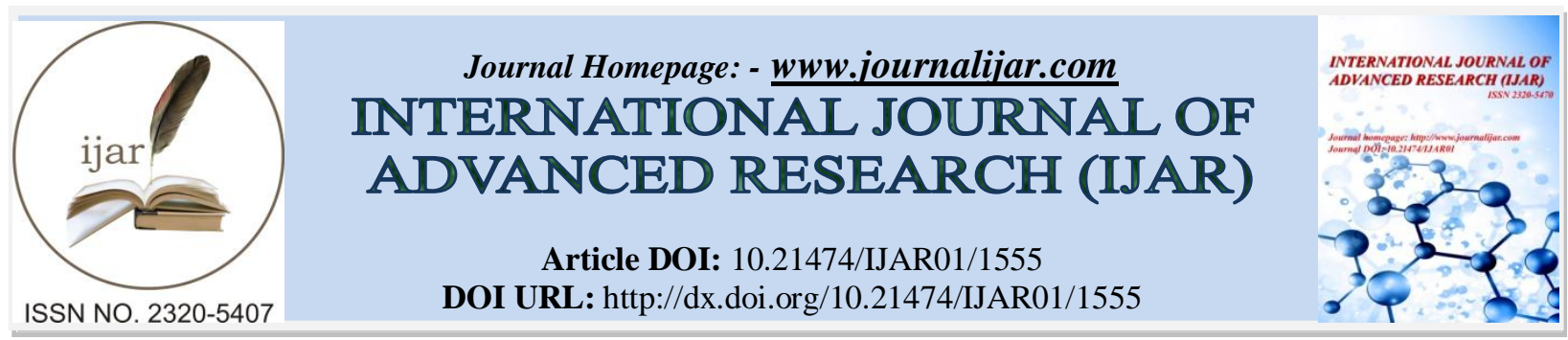

RESEARCH ARTICLE

\title{
DILACERATION.... A FREQUENTLY ENCOUNTERED CHALLENGE IN DENTAL TREATMENTS!!
}

\section{Dr. Romita Dilip Gaikwad.}

Senior Lecturer, Department of Oral Medicine \& Radiology, Swargiya Dadasaheb Kalmegh Smruti Dental College \& Hospital, Nagpur, Maharashtra, India.

\section{Manuscript Info}

Manuscript History

Received: 15 July 2016

Final Accepted: 15 August 2016

Published: September 2016

Key words:-

Dilaceration, Amelocemental junction,

Orthopantomograms

\section{Abstract}

Almost all teeth have roots with an angulation at some point along the long axis. Dilaceration refers to an angulation that may occur anywhere along the length of the tooth, that is, its crown, amelocemental junction, along the root or by only involving the apex of the root. ${ }^{1}$ The most widely accepted cause is mechanical trauma to the primary predecessor tooth, which results in dilaceration of the developing permanent tooth. An idiopathic developmental disturbance is proposed as another cause in cases that have no clear evidence of traumatic injury. ${ }^{2}$ Diagnosing dilaceration is critical as severely angulated roots of teeth may complicate dental treatments like root canal treatment, extraction and orthodontic treatment. Thus, root angulation of teeth influences the planning and execution of dental treatment to varying extents. ${ }^{3}$

Although dilaceration of a crown can be visually observed in an intraoral inspection, radiographic examination is required to diagnose dilaceration of a tooth root. Orthopantomograms may be routinely employed as an initial screening or diagnostic modality to determine the extent of dilaceration. ${ }^{2}$ In the literature only few articles have reported the prevalence of dilacerations. Thus, the following study was done to evaluate the prevalence of root dilacerations in central India population with respect to gender, jaws, dental localization as well as to measure the extent of dilacerations in an individual tooth.

Copy Right, IJAR, 2016,. All rights reserved.

\section{Introduction:-}

Dilaceration even though is a less frequently observed dental anomaly, it causes a great difficulty in many dental treatments like endodontic treatment, orthodontic treatment and in extraction procedures. Dilaceration is an angulation or bend in the root or, less frequently, the crown of a tooth. ${ }^{1}$ The etiology of dilacerations can be attributed to 2 possible factors and among this the most widely accepted cause is mechanical trauma to the primary predecessor tooth. In cases, where clear evidence of traumatic injury is absent, dilaceration is considered as an idiopathic developmental disturbance.

To diagnose a dilacerated crown, clinical examination is sufficient. However, to diagnose a dilacerated root radiographic examination is necessary. There is a great variability in the literature regarding the criteria required for the diagnosis of root dilacerations. ${ }^{2}$ Some authors define a tooth to have dilaceration towards the mesial or distal direction if there is a $90^{\circ}$ angle or greater along the axis of the tooth or root, while some define dilacerations as a 
deviation from the normal axis of the tooth of $20^{\circ}$ or more in the apical portion of the root. There is however little information regarding the prevalence of dilacerations as many of the published articles are case reports of dilacerations pertaining to a single permanent tooth. Also, only few studies have reported the prevalence of dilacerations in multiple permanent teeth in adults. Thus, the aim of the present study was to evaluate the prevalence of root dilacerations using orthopantomograms.

\section{Material and methods:-}

A retrospective study was carried out using a total of 400 OPG's with full complement of teeth made in the year 2011-2013 in the Department of Oral Medicine and Radiology, VSPM's Dental College and Research Centre, Nagpur. The exclusion criteria included patients who were having deciduous or mixed dentition, patients who were undergoing orthodontic treatment and radiographs having poor quality. The analysis of the radiographs was done by a single examiner with the help of a magnifying lens and an X-ray viewer. To determine the long axis of each tooth a ruler was used and was aligned along the pulp of the tooth. With the help of the protractor, the angle made by the root to the long axis of the tooth was measured (Figure - 1). Root angulations in mesial or distal direction starting from $20^{0}$ were measured. ${ }^{3}$ Also, the extent of root dilaceration was further categorised as mild- when the extent of root dilaceration was in the range of $20^{\circ}-40^{\circ}$; moderate- when the extent of root dilaceration was in the range of $40^{\circ}$ $60^{\circ}$; severe - when the extent of root dilaceration was $>60^{\circ}$. The data was entered in a predesigned proforma and statistical analysis was done using the computer program Statistical Package for the Social Science (SPSS), version 14. To compare data among the groups Chi-square test was used.

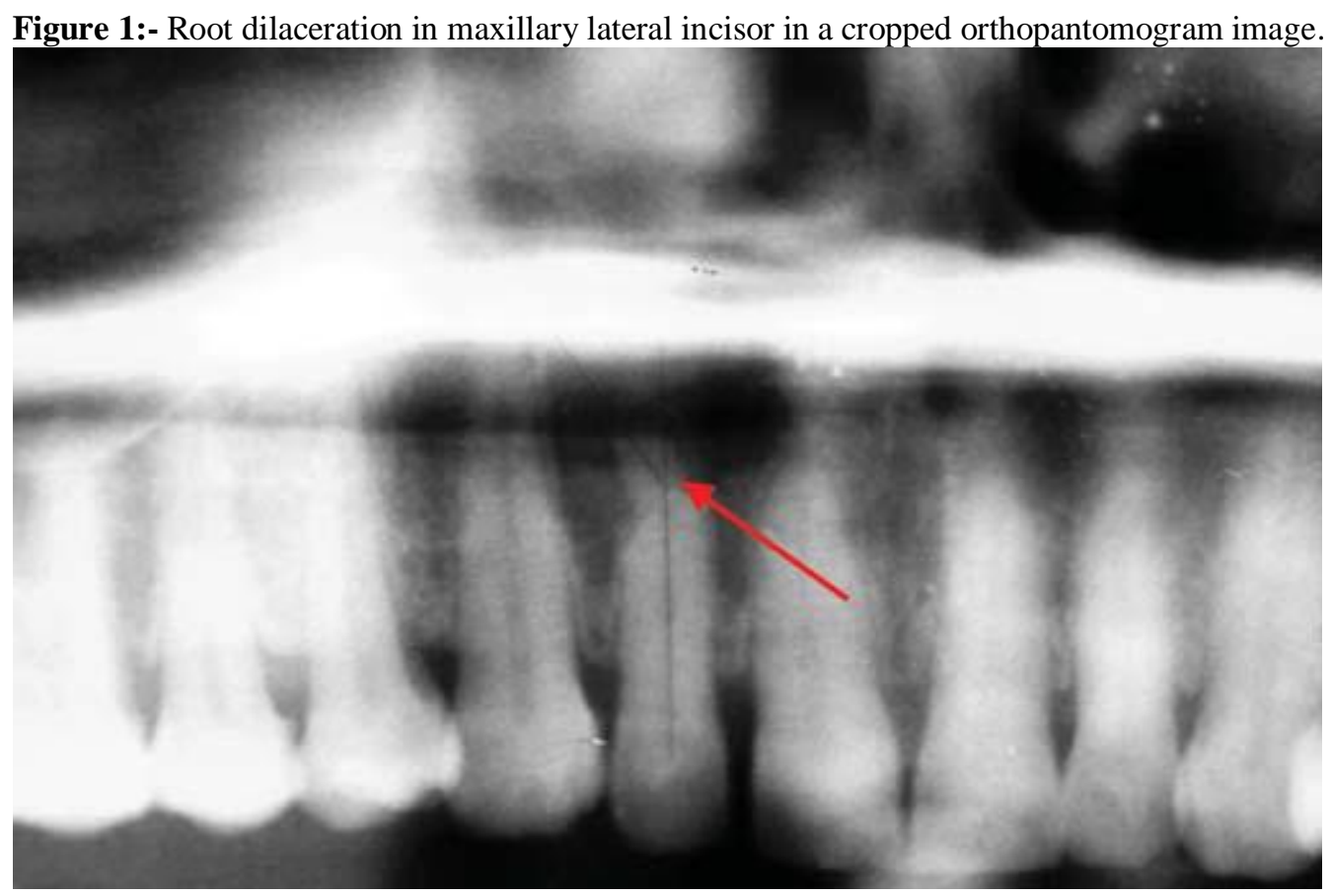

\section{Results:-}

Out of the 400 OPG's screened, root dilacerations was prevalent in $322(80.5 \%)$ OPG's. The male to female ratio was not statistically significant ( $\mathrm{p}=0.164)$. The prevalence of root angulation among the various teeth in the maxilla and the mandible is presented in table 1-3. The prevalence of root dilacerations was more when it was present simultaneously in both the arches and the results were highly significant $(\mathrm{p}<0.0001)$. Root dilacerations was maximum in maxillary lateral incisors followed by mandibular third molars and mandibular first molar. The teeth like mandibular anteriors, maxillary centrals, maxillary canine and maxillary first premolar were the least affected tooth by dilaceration. 
Table 1:- Number of teeth with root angulations on right and left side in Maxillary arch.

\begin{tabular}{|l|l|l|l|}
\hline & Maxillary Teeth & Right & Left \\
\hline Tooth Type & Number & $1(2.3)$ & $2(4.5)$ \\
\hline Central & 44 & $24(54.5)$ & $19(43.2)$ \\
\hline Lateral & 44 & $2(4.5)$ & $2(4.5)$ \\
\hline Canine & 44 & $3(6.8)$ & $4(9.0)$ \\
\hline First Premolar & 44 & $5(11.4)$ & $2(4.5)$ \\
\hline Second Pre molar & 44 & $1(2.3)$ & $2(4.5)$ \\
\hline First Molar & 44 & $4(9.0)$ & $2(4.5)$ \\
\hline Second Molar & 44 & $1(2.3)$ & $1(2.3)$ \\
\hline Third molar & 44 & & \\
\hline
\end{tabular}

Table 2:- Number of teeth with root angulations on right and left side in Mandibular arch.

\begin{tabular}{|l|l|l|l|}
\hline \multicolumn{2}{|l|}{ Mandibular Teeth } & Right & Left \\
\hline Tooth Type & Number & 0 & 0 \\
\hline Central & 93 & 0 & 0 \\
\hline Lateral & 93 & $2(2.1)$ & $4(4.3)$ \\
\hline Canine & 93 & $12(12.9)$ & $16(17.2)$ \\
\hline First Premolar & 93 & $14(15.0)$ & $14(15.0)$ \\
\hline Second Pre molar & 93 & $22(23.6)$ & $24(25.8)$ \\
\hline First Molar & 93 & $13(13.9)$ & $21(22.6)$ \\
\hline Second Molar & 93 & $31(33.3)$ & $41(44.0)$ \\
\hline Third molar & 93 & & \\
\hline
\end{tabular}

Table 3:- Number of teeth with root angulations on right and left side in Maxillary and Mandibular arch.

\begin{tabular}{|l|l|l|l|l|l|}
\hline & \multicolumn{2}{|l|}{ Maxillary } & \multicolumn{2}{l|}{ Mandibular } \\
\hline Tooth Type & Number & Right & Left & Right & Left \\
\hline Central & 185 & 0 & 0 & 0 & 2 \\
\hline Lateral & 185 & 0 & 0 & 79 & 65 \\
\hline Canine & 185 & 6 & 11 & 10 & 6 \\
\hline First Premolar & 185 & 27 & 33 & 13 & 6 \\
\hline $\begin{array}{l}\text { Second Pre } \\
\text { molar }\end{array}$ & 185 & 29 & 25 & 26 & 24 \\
\hline First Molar & 185 & 69 & 60 & 10 & 10 \\
\hline Second Molar & 185 & 26 & 32 & 34 & 14 \\
\hline Third molar & 185 & 41 & 64 & & 11 \\
\hline
\end{tabular}

This is the first study in the literature in which prevalence of root dilacerations among the right and left side of maxillary and mandibular arches was compared. However, the comparison among the right and left sides of jaws was not statistically significant.

\section{Discussion:-}

The term dilaceration was coined by Tomes in $1848^{4}$. Diagnosing dilaceration is critical as severely angulated roots of teeth may complicate dental treatments like root canal treatment, extraction and orthodontic treatment. Thus, dilacerations influences the planning and execution of dental treatment to varying extents.

Routinely orthopantomograms may be employed as an initial screening or diagnostic modality, however when necessary further follow up using periapical radiograph can be done as periapical radiographs more accurately determine the extent of dilaceration. Although, not a routine diagnostic tool, cone beam computed tomography (CBCT) i.e. the three dimensional examination of root dilacerations may provide a comprehensive picture. The literature, however is insufficient with regards to the availability of data regarding the prevalence of dilacerations. 
Hamasha et al conducted a study using periapical radiographs to record dilacerations. ${ }^{5}$ In the present study, orthopantomograms were used as a practical tool. $80.5 \%$ of the orthopantomograms screened were found to have root dilacerations as compared to a study by Omal et al who found dilacerations only in 50\% of orthopantomograms.

In both the studies, no statistically significant difference was found between males and females. The results of the present study was however in contrast to those obtained in a study by Ezzoddini et al, in which the prevalence was significantly higher in males than in females. The prevalence of root dilacerations present in both the maxillary and mandibular arches has not been reported previously. In our study, it was observed that the prevalence of root dilacerations was significantly more when root dilacerations was present in both the arches $(\mathrm{p}<0.0001)$. The prevalence rate of root dilacerations was maximum in maxillary laterals $(54.5 \%)$ which was in accordance in study by Chohayeb et al. After maxillary laterals, mandibular third molar (41\%) followed by mandibular first molar (24\%) were most affected which was in agreement with the study by Hamasha et al. Root dilacerations was not detected in mandibular anterior teeth which was in accordance with the study by Miloglu et al.

Severe degree of dilacerations was seen in mandibular third molars followed by maxillary second and third molars which was in contrast to the study by Omal et al.

\section{Conclusion:-}

Root dilacerations was most prevalent in maxillary lateral incisors. Although, intraoral periapical radiographs are more useful to evaluate root dilacerations, orthopantomograms can be used to evaluate root dilacerations in full complement of teeth. Since there exists a difference in root angulation values in studies from different populations, more studies may be necessary to know the exact prevalence, if any, of individual type of tooth in maxillary and mandibular arches.

\section{References:-}

1. Neville B, Damm D, Allen C, Bouquot J (2010): Textbook of Oral and Maxillofacial Pathology. $3^{\text {rd }}$ edition. Haryana, Elsevier; 97.

2. Miloglu O, Cakici F, Caglayan F, Yilmaz A, Demirkaya F (2010): The prevalence of root dilacerations in a Turkish population. Med Oral Patol Oral Cir Bucal; 15(3):e441-4.

3. Omal PM, Thomas S, John J, George B, Mathew A (2012): The extend of root angulation in patients visiting a dental school in South Kerala: A Panoramic Radiographic Study. JIAOMR; 24(3):186-189.

4. Jafarzadeh H, Abbott P (2007): Dilaceration: Review of an Endodontic Challenge. J Endod ; 33: 1025-1030.

5. Hamasha AA, AL-Khateeb T, Darwazeh A (2002): Prevalence of dilaceration in Jordanian adults. Int Endod J; 35:910-12.

6. Malcic A, Jukic S, Brzovic V, Miletic I, Pelivan I, Anic I (2006): Prevalence of root dilaceration in adult dental patients in Croatia. Oral Surg Oral Med Oral Pathol Oral Radiol Endod ;102: 104-09. 